\title{
OS LUSÍADAS E O MARIALVISMO NA ESCOLA NOVA DE SALAZAR
}

Flávio Garcia Vichinsky ${ }^{1}$

\begin{abstract}
RESUMO: O regime político português que ficou conhecido como Estado Novo teve por característica um discurso sedimentado em valores morais, religiosos e cívicos. O presente trabalho busca mostrar de que forma tal discurso, que pretendemos caracterizar como potencialmente marialva, influenciou a adaptação do poema épico camoniano para a leitura infanto-juvenil, realizada nas escolas daquele período. Para tanto, confrontaremos uma dessas obras adaptadas com alguns dos elementos da política de Salazar, e estes com o que José Cardoso Pires aponta como marialvismo.
\end{abstract}

PALAVRAS-CHAVE: Portugal, Salazar, Escola, Mariahismo, Camões.

ABSTRACT: The political regime that was known in Portugal as Estado Novo has used a discourse that was based on moral, religious and civic values. This paper wants to show how this discourse, that we want to characterize as potentially "marialva", has influenced the adaptations pieces of the camonian epic poem for children's reading, which was held in the schools of that period. For this, we want to confront one of these adapted pieces with some of the elements of the Salazar's policy, and these with what Jose Cardoso Pires points as "marialvismo".

KEYWO RDS: Portugal, Salazar, School, Marialvismo, Camões.

\section{INTRODUÇÃO}

Pôde-se dizer tudo o que se quis a respeito de Camões. Uma vez postulado como elemento mítico, ícone de uma cultura, alojou-se de tal forma no imaginário português que, tirante a palavra de Deus ${ }^{2}$, foi enquadrado como exemplo para todos e, por isso, pintado com tintas e pincéis tão diferenciados quanto os interesses subjacentes em tais retratos. Já no século XIX escrevia Oliveira Martins, a respeito do alarde praticamente irracional das comemorações de 1880, “O povo, quando se extasia admirativamente, é incapaz de dar razão ao seu acto, porque é a si próprio que, por uma ilusão subjectiva, se consagra no símbolo que venera". (MARTINS, 1952, p. 6).

E não apenas durante as comemorações do terceiro centenário, mas repetidamente o vate foi convocado de tempos em tempos para manter alimentada tal ilusão subjetiva, tal veneração especular capaz de eclipsar a própria razão. Constituindo-se como mito, geração

\footnotetext{
${ }^{1}$ Mestre em Letras e doutorando em Literatura Portuguesa pela USP.

${ }^{2}$ Segunda fala do personagem Telmo, na Cena II do Frei Luís de Sousa de Almeida Garrett.
} 
após geração, Camões vem servindo para quase tudo e a quase todos, como arremata Oliveira Martins no mesmo texto:

Para o ateu, é ateu; para o republicano, é uma espécie de Catão. O próprio petroleiro será capaz de achar no poeta o seu precursor; da mesma forma que o erudito descobre um Camões scholar, e o reacionário se acha retratado no amor do trono e do altar. O estouvado cria um Camões brigão; e o pacato e honrado mercador descrevê-lo-á homem de sereno porte, gestos medidos, bom filho, bom esposo, bom pai, econômico, sabendo governar a vida, e capaz de ganhar dinheiro: um gênio! (MARTINS, 1952, p. 9).

$\mathrm{Na}$ verdade, o que vemos aqui é o indício de uma multiplicidade de leituras possíveis da obra camoniana, orientadas por tal ou qual perspectiva, por esta ou aquela motivação especial e isso é perceptível nas notas introdutórias, biografias, comentários e demais escritos presentes nas diversas edições de Os Lusíadas ou das Rimas. É nesses textos que introduzem ou circundam os versos camonianos que se encontram as pistas da recepção pretendida na época, o que pode nos revelar, ora com maior ênfase, ora menor, a possível intencionalidade dos projetos editoriais como, por exemplo, na edição do épico levada a efeito pelo Morgado de Mateus, obra considerada como um monumento ao orgulho português, publicada em 1817, momento em que o país encontrava-se fragilizado pelo distanciamento dos seus governantes instalados no Brasil. O mesmo pode ser apontado em outra situação mais pertinente a este trabalho, ou seja, aquilo que ocorreu nas edições escolares estado-novistas.

Como se sabe, o Estado Novo em Portugal teve o seu início historicamente assinalado em 1933, com a promulgação da nova constituição. No entanto, os mesmos ideais antiliberais e antiparlamentares característicos desse regime político - sabidamente conhecido por adotar um discurso conservador e reacionário - podem ser observados desde a Revolução Nacional, que pôs fim aos ideais democráticos da Primeira República, em 1926. A figura de maior destaque na política desse período é a de Antônio de Oliveira Salazar, que dirigiu o país atuando em linhas bastante austeras. Frente a essas características mais marcantes do referido período, é bastante plausível que nós aproximemos de tal regime - também conhecido como salazarismo - do que em Portugal se conhece como marialvismo - um modo de ser ou conduta baseado em paradigmas conservadores, machistas e autoritários.

Isto posto, buscaremos agora estabelecer uma relação entre a ideologia política salazarista e o discurso presente em uma das adaptações de Os Lusíadas usada na escola 
durante esse período, procurando situá-los dentro de um horizonte de expectativas que pode ser considerado predominantemente marialva. Para isso serão invocados, por um lado, José Cardoso Pires (JCP) e a sua Cartilha do Marialva (CM) e, pelo outro, João de Barros (JB) e a sua adaptação de Os Lusiadas (LusAd).

\section{CAMÕES A SERVIÇO DA PÁTRIA}

Como se sabe, a nova escola salazarista, assim como todas as instituições oficiais daquela época, foi pautada em um modelo social orientado pelas diretrizes do nacionalsocialismo do Estado Novo, regime político caracterizado pela repressão ${ }^{3}$ e pelo nacionalismo extremado ${ }^{4}$.

A religião, a família e a pátria ocupavam papel de destaque nessa concepção e a educação popular foi um dos meios mais eficientes encontrados pelos governantes para semear o que viria a servir como base para a edificação de uma sociedade, viril, patriarcal e conservadora. A materialidade dessa ação ficou registrada em diversos elementos ligados à escola e à educação de forma geral, tal como em $A$ lição de Salazar ${ }^{5}$, na lei 1.941 de $11 / 04 / 1936^{6}$ e na literatura voltada aos jovens e crianças, entre elas as edições escolares de Os Lusiadas.

Dentre inúmeras edições do poema, pode-se tomar como referência a adaptação em prosa do épico camoniano intitulado Os Lusíadas - contados às crianças e lembrados ao povo, do professor João de Barros. Trata-se de um livro adotado em larga escala pelas escolas portuguesas à época do salazarismo. Nesse livro, em especial no prefácio e na biografia do poeta, é possível perceber a presença de um discurso notadamente afim com as diretrizes governistas. Palavras como "honra", "pátria" e "dever", dentre outras, revelam certo posicionamento conservador e, evocando José Cardoso Pires, "antilibertino", ou "marialva", termos pouco invulgares na literatura portuguesa do século XX, quando se trata dos assuntos ligados ao regime de Salazar.

\footnotetext{
${ }^{3}$ Exemp lo dis so é a criação da Polícia Política que, de acordo com NETTO (1986), teve o as ses soramento dos nazistas alemães.

4 A própria Constituição de 1933, além de outras le is, como o "Ato Colonial”, atestam tal característica.

5 Em 1938 Salazar mandou imprimir uma série de sete cartazes de cunho ultranacionalista, os quais deveriam ser afixados em cada sala de aula.

${ }^{6}$ De acordo com essa lei, em sua base XIII, “Em todas as escolas públicas do ensino primário infantil e ele mentar existirá, por detrás e acima da cadeira do professor, um crucifixo, co mo símbolo da educação cristã determinada pela Constituição".
} 
Para que se estabeleça uma caracterização, necessária para que levemos a efeito as aproximações entre um e outro discurso, lembremos que, de acordo com JCP,

Marialva é o antilibertino português, privilegiado em nome da razão de Casa e Sangue, cuja configuração social e intelectual se define, nas suas tonalidades mais vincadas, no decorrer do século XVIII.

No convencionalismo popular (ou antes pequeno-burguês) marialva é o fidalgo (forma primitiva de "privilegiado") boémio e estoura-vergas. Socialmente será outra coisa: um indivíduo interessado em certo tipo de economia e em certa fisionomia política assente no irracionalismo. (PIRES, 1967, p. 11)

O marialvismo, assente nas relações feudais reminiscentes da Idade Média, tem o seu discurso impregnado por uma visão patriarcal e tradicionalista, autoritária e reacionária, dogmática e centralizadora. O sujeito do discurso marialva se dirige ao seu interlocutor pretendendo-o como objeto dócil, útil, ligado às tradições e à identidade e, acima de tudo, incapaz de estabelecer-se como senhor de si mesmo, portanto servil. Esse tipo de discurso, coerente com o que se percebe nas ações do governo salazarista, pode ser encontrado em JB, no seu LusAd: "Para ele [Camões], a Pátria estava acima de tudo - e não fez outra coisa, durante a sua vida inteira, senão louvar as virtudes do seu povo e dos seus heróis, ou lutar para a fazer respeitada e admirada por todos". (BARROS, 1998, p. 202). Esse é um trecho da biografia de Luís de Camões que ocupa as sete últimas páginas do livro.

Note-se aqui a caracterização do poeta quinhentista como patriota aguerrido, dando o seu corpo ("lutar") e o seu espírito ("louvar") em favor de Portugal. Essa entrega total ou submissão na relação entre o que manda e aquele que obedece -, que também faz parte da ontologia marialva, é provavelmente expressa aqui para que o "bom português" veja um exemplo a ser seguido. Além disso, a adjetivação do povo como sendo virtuoso e, no seio desse a prevalência de alguns heróis, faz com que os versos do poema épico - mesmo que não lidos - sejam dignos de aplauso, recurso retórico de JB que torna ainda mais eficiente o seu argumento de cunho patriota.

Voltando à questão da submissão, podemos perceber ainda, nessa obra adaptada, a existência de uma atmosfera feudal, fundada em questões econômicas, que dignifica os senhores e mostra que a obediência a estes é o único caminho correto a ser seguido. Vejam-se, por exemplo, estas palavras da mesma biografia: "Como era pobre [Camões], aceitou a proteção de seu tio D. Bento, sacerdote e sábio, que o ia guiando nos estudos" 
(BARROS, 1998, p. 203), “O pior de tudo é que o poeta não tinha fortuna - e a menina era rica. Ora, nesse tempo, os pobres não se casavam com os ricos" (BARROS, 1998, p. 204) ${ }^{7}$.

O assentamento da assimetria entre as duas classes sociais é acompanhada por um conformismo indiscutível. Nesta biografia, o poeta não se mostra indignado com a dura realidade que o circunda, tampouco se revolta contra o "desconcerto do mundo", nela JB constrói um Camões passivo e submisso, que recebe todo e qualquer golpe como "mais um contratempo, que o poeta sofreu sem queixas" (BARROS, 1998, p. 212). A aproximação dessa prefiguração com o que aponta JCP na sua CM é digna de comentários:

\begin{abstract}
Depois da moral das resignações imposta à esposa no amável universo concentracionário do lar (divinização do Pater-Familias), vem o apelo às resignações do servo em face da ordem cósmica da qual depende a fome nos campos; depois do paternalismo doméstico, alarga-se o paternalismo ao nível da governação, "o braço tocado por Deus", digamos, que dispensa a opinião do governado e o mantém à margem dos negócios públicos. (PIRES, 1967, p. 190)9.
\end{abstract}

É quase impossível abstermo-nos de pensar no regime salazarista quando lemos em JCP sobre a resignação do servo e a dispensa de opinião do governado. Partindo das relações estabelecidas no seio do lar, onde o português caracterizado como marialva exerce uma ação centralizadora e arrogante frente à figura da mulher, JCP amplia essa mesma perspectiva para as questões de governo. Em contraste com a clareza de intencionalidade da CM em apontar a prepotência de um governo austero, é aceitável dizer que talvez JB não tivesse a intenção consciente de promover um discurso fundamentado no espírito marialva, e nem pensasse em contribuir para a manutenção de um governo predominantemente autoritário e centralizador. No entanto, o cerne do que lemos em seu Lus Ad aponta inegavelmente para essa direção. A figura do Pater-Famílias como guardião das tradições intocáveis subjaz de forma a impregnar todo o texto com o mesmo ânimo marialva que JCP percebe nos "conselheiros da portuguesidade": D. Francisco Manuel de Melo em Carta de Guia de Casados, Almeida Garrett no Viagens na Minha Terra, Júlio Dinis em Uma Família Inglesa, Eça de Queirós em Uma Campanha Alegre, Teixeira de Pascoaes em Arte de Ser Português, e outros no tempo da propaganda salazarista (PIRES, 1967, pp. 131172). Aliás, talvez sejam esses os mesmos portugueses postulados por JB como "bons e

\footnotetext{
${ }^{7}$ Grifos meus.

${ }^{8}$ O que contrasta com a própria produção poética de Camões, a exemplo de "Os bons sempre vi passar" (RI, 183) e "Quem pode ser no mundo tão quieto" (RI, 82).

${ }^{9}$ Grifos meus.
} 
sinceros patriotas". (BARROS, 1998, 203). Ao longo dessa biografia escrita por JB, percebemos que, para ele, ser "bom português" é o mesmo que ser "português patriota", o que significava fundamentalmente assumir Portugal como uma nação destinada à grandeza, à espera de cumprir o seu destino.

Enquanto Portugal não conquistou a independência, [Os Lusíadas] foram a leitura fiel daqueles que precisavam de fortalecer a sua confiança na Pátria e no Povo oprimidos. Hoje ainda - hoje e sempre o poema de Luís de Camões ensina a estrangeiros e a nacionais $\underline{a}$ grandeza e a eternidade do destino de Portugal. (BARROS, 1998, p. 214)..$^{10}$

Fazer com que o povo acreditasse que o país podia resgatar de um passado glorioso a prosperidade e riqueza necessárias para fazer de Portugal uma grande nação frente à Europa também foi uma das estratégias de propaganda do regime salazarista. Isso tudo se condensa no olhar saudosista e messiânico que encontramos em ambos os discursos, ou seja, mais uma vez aqui se cruzam os caminhos de Salazar e JB, sob a capa e a espada do marialvismo. JCP faz referência a esse modo de ser, voltado para as coisas do passado, como um dos atributos do marialva:

Primitivo e violento, feudal nas relações da terra e do servo, e sebastianista (forma cristalizada do messianismo racista), o marialva dispunha de uma experiência que o Nacional-Socialismo veio enriquecer. A força cesárea do poder, a reimplantação dos rituais romanos e medievais deram-lhe uma oportunidade salvadora de estruturar a sua dogmática instintiva. (PIRES, 1967, p. 133).

É compreensível esse provável posicionamento ideológico de JB quando nos lembramos do período histórico em que se insere o seu trabalho. Foram muitas as instabilidades sentidas pelo povo durante a Primeira República, oriunda de um intenso movimento liberal e antimonarquista que remonta ao vintismo e ao setembrismo. Em especial, preocupava o clima revoltoso e a ameaça constante de novos golpes que proporcionavam ao país um ambiente de insegurança e incertezas.

O golpe de 28 de maio, que instaurou a ditadura portuguesa em 1926, trouxe para muitos uma nova esperança que podemos compreender se levarmos em conta o "mito do

\footnotetext{
${ }^{10}$ Grifos meus.
} 
caráter dócil e pacífico do povo português" (NETTO, 1986, p. 14) e o apego sentimental a um passado de glórias e conquistas.

Assumindo o discurso conservador marialva, JB não se coloca diretamente a favor de um regime político, mas dá indícios de uma sintonia com os princípios antiliberais que procuram resgatar no passado histórico português - e, portanto, nas tradições - os elementos exemplares para a conquista da felicidade nacional. Essa é uma atitude perfeitamente condizente com os anseios populares desse período instável e, diga-se mais, condizente com o sentido mais amplo e geral da "alma portuguesa", na forma como aponta Eduardo Lourenço:

É esse lugar de sonho, esse lugar ao abrigo do sonho, esse passadopresente, que a "alma portuguesa" não quer abandonar. Para o não abandonar - antes mesmo que esse passado se tivesse tornado historicamente mítico, como tempo glorioso das Descobertas ou infeliz de Alcácer Quibir -, Portugal, imerso com doçura no mundo, natural e sobrenaturalmente maravilhoso, converteu-se em ilha-saudade. (LOURENÇO, 1999, pp. 91-92).

Portugal como destino, Portugal como ilha voltada ao passado, perpetuamente ligada por um misticismo irracional àquilo que foi outrora. Um país que se basta por si, desvinculado do contexto mundial por se reconhecer tão pequeno e, por isso mesmo, pleno de virtudes morais. Tal é o sentido que adquire a "alma portuguesa", a alma do povo português, a alma de muitos portugueses que aceitaram pacificamente tudo quanto foi feito pelo governo de Salazar. Explorar esse modo de ser, essa característica cultural, também foi a estratégia adotada por muitos educadores sintonizados com o salazarismo, no intuito de manterem-se as tradições, ou seja, fazer com que Portugal perpetuasse o contato com as próprias origens, como "ilha saudade". Isso justifica a presença privilegiada do poema épico de Camões e do próprio poeta na escola de Salazar como emblemas e fontes de inspiração, no intuito de que tais tradições mantivessem miraculosamente a unidade do país heri, nunc et semper, amém.

\section{CONCLUSÃO}

O horizonte de expectativas denunciado pela leitura desses paratextos, da edição adaptada de Os Lusíadas e a programação de leitura que neles se dão, não são isentos de 
uma intencionalidade, mesmo que ligada de forma inocente aos ideais do nacionalsocialismo salazarista.

A percepção desse apreço pelas tradições e pelo status quo de uma sociedade fundamentada por relações servis nos leva a ponderar até que ponto a escola, investigada aqui nessa ínfima parcela que se reduz apenas a uma parte de uma só obra, fomentou a concepção de Portugal como destino. Quantos outros discursos implícitos nos diversos materiais didáticos adotados pela nova escola foram determinantes para a difusão dos ideais de um governo cujas diretrizes são tão questionáveis quanto questionável é a postura do marialva frente ao mundo moderno.

A escolha de Camões como o arauto do destino de Portugal, sobejamente perceptível no livro escolar de JB, é um assunto também abordado na CM, mas, como já se poderia deduzir, de maneira crítica:

O sebastianismo marialva elegeu Camões em nome da entronização da raça e dos destinos superiores que a Providência entendeu reservar aos bons portugueses. Em nome até do direito de colonizar e do espírito de cruzada. Mas a revisão impôs Camões por motivos totalmente opostos e sobretudo depois da meditação portuguesa sobre o universalismo. (PIRES, 1967, p. 51).

Camões e Os Lusíadas foram úteis ao regime político ostracista ${ }^{11}$ de Salazar. Coube à escola direcionar a leitura do poema de acordo com os interesses nacionalistas do Estado Novo e o papel dos adaptadores do poema, dentre eles JB, foi decisivo para tal intento.

Ao reescrever os versos de Camões em prosa corrente, JB tencionava "criar nas almas infantis o civismo de que tanto falamos e de que tanto carecemos" (BARROS 1998, p. 10). E não se pode dizer que tal intenção estava em desacordo com o governo.

Apesar das duras investidas contra as correntes de pensamento liberais e divergentes daquelas preconizadas pelo ensino da nova escola, hoje, com distanciamento histórico necessário, podemos concluir que o espírito marialva jamais conseguiu suplantar em definitivo o seu oposto, o libertino. JCP é bastante feliz quando escreve a respeito disso na sua CM:

Vê-se agora que já não são apenas as condenações libertinas e o liberalismo econômico que pesam sobre a existência marialva. É o tempo - tempo histórico, medido nas formas científicas e concretas a que obriga a convivência das nações no mundo actual. (PIRES, 1967, p. 193).

\footnotetext{
${ }^{11}$ Um dos lemas do governo de Salazar era "orgulhosamente sós". (NETTO, 1986, p. 25).
} 
O transcorrer do tempo histórico e as obrigações impostas pela crescente e inevitável mundialização impõem a Portugal um novo destino. Isso indica que o Camões da leitura marialva, provinciano e antilibertino, como se vê na proposta de JB, é apenas um entre tantos outros possíveis. Faz-se imprescindível um novo paradigma em que as possibilidades dilatem-se. E admitir essa possibilidade plural é admitir a multiplicidade de ideias e manifestações. Em última análise, admitir a tão necessária liberdade para ler e a liberdade para ser.

\section{REFERÊNCIAS BIBLIOGRÁFICAS}

BARROS, João de. Os Lusíadas - Contados às Crianças e Lembrados ao Povo. Lisboa: Livraria Sá da Costa Editora, 1998.

GARRETT, Almeida. Frei Luis de Souza. Porto: Ideias a Ler Editora, 2010.

LOURENÇO, Eduardo. Mitologia da Saudade. São Paulo: Companhia das Letras, 1999.

MARTINS, Oliveira. Camões - Os Lusíadas e a Renascença em Portugal. Lisboa: Guimarães \& Cia. Editores, 1952.

NETTO, José Paulo. Portugal - do Fascismo à Revolução. Porto Alegre: Mercado Aberto, 1986. PIRES, José Cardoso. Cartilha do Marialva - ou das Navegaçoes Libertinas. Lisboa: Ulisseia, 1967.

Artigo recebido em 15 de Março de 2012 e aprovado em 18 de Abril de 2012 